
of Life Questionnaire (AAOLL)

\title{
Validade de constructo e confiabilidade da versão em língua portuguesa do Questionário de Qualidade de Vida em Adultos que apresentam TDAH (AAQoL)
}

\author{
Paulo Mattos ${ }^{1}$, Daniel Segenreich ${ }^{1}$, Gabriela Macedo Dias¹, Bruno Nazar ${ }^{1}$, Eloisa Saboya ${ }^{1}$, Meryl Broad² \\ I GEDA - Attention Deficit Study Group, Institute of Psychiatry, Universidade Federal do Rio de Janeiro (UFRJ). \\ 2 The Brod Group.
}

Received: $19 / 72010$ - Accepted: 30/9/2010

\begin{abstract}
Background: Several studies demonstrate that attention deficit hyperactivity disorder (ADHD) in adults is related to worse measures of quality of life. Objective: To evaluate the reliability and construct validity of the Portuguese version of the Adult ADHD Quality of Life Questionnaire (AAQoL). Methods: Adults with age ranging from 18 to 60 years old were included in this study. According to their diagnostic status they were divided into three groups: a) ADHD subjects using DSM-IV criteria; b) subjects with subthreshold ADHD; c) control comparison group without ADHD. The following questionnaires were applied: ASRS; SF-36 and AAQoL. The first part of the study evaluated the construct validity of the instrument and in the second part its reliability was tested. Results: ADHD, subthreshold ADHD and control groups comprised 29, 18 and 29 subjects, respectively. We found a negative correlation between the number of symptoms (ASRS) and the AAQoL total score considering all three groups. ADHD group presented worse levels of quality of life when compared to control group. As a whole, AAQol scores had significant correlation with SF-36 scores. Results indicated high levels of internal consistency and test-retest reliability. Discussion: The AAQoL construct presented high internal consistency of items, stability and construct validity.
\end{abstract}

Mattos P, et al. / Rev Psiq Clín. 2011;38(3):91-6

Keywords: Translating, attention deficit hyperactivity disorder, quality of life, validation studies.

\section{Resumo}

Introdução: Diversos estudos demonstram que o transtorno de déficit de atenção/hiperatividade (TDAH) em adultos está relacionado a piores medições de qualidade de vida. Objetivo: Avaliar a validade e confiabilidade de constructo da versão em língua portuguesa do questionário de qualidade de vida em adultos com TDAH (AAQoL). Métodos: Foram incluídos neste estudo adultos com idade entre 18 e 60 anos. Eles foram divididos em três grupos de acordo com o diagnóstico: a) indivíduos com TDAH com base nos critérios do DSM-IV; b) indivíduos abaixo do limite de TDAH; c) grupo controle de comparação que não apresenta TDAH. Foram aplicados os seguintes questionários: ASRS, SF-36 e AAQoL. A primeira parte do estudo avaliou a validação de constructo do instrumento e a segunda parte testou sua confiabilidade. Resultados: Os grupos TDAH, TDAH abaixo do limite e controle abrangeram 29,18 e 29 indivíduos, respectivamente. Considerando todos os três grupos, encontramos uma correlação negativa entre o número de sintomas (ASRS) e a pontuação total do AAQoL. O grupo TDAH apresentou os piores níveis de qualidade de vida quando comparado com o grupo controle. No geral, as pontuações do AAQoL tiveram correlação significativa com as da SF-36. Os resultados indicaram altos níveis de coerência interna e confiabilidade dos testes e retestes. Conclusão: O constructo do AAQoL apresentou altos níveis de coerência interna dos itens, estabilidade e validade de constructo.

Mattos P, et al. / Rev Psiq Clín. 2011;38(3):91-6

Palavras-chave: Tradução, transtorno do déficit de atenção/hiperatividade, qualidade de vida, estudos de validação.

\section{Introduction}

The adult form of attention deficit hyperactivity disorder (ADHD) - previously called "residual type" - was officially recognized by the American Association of Psychiatry in 1980. Longitudinal studies have demonstrated that ADHD persists in adult life in about $60 \%$ to $70 \%$ of cases, with differences found in remission rates well attributed to different ADHD definitions over time than disorder course during lifetime ${ }^{1,2}$. Different research employing several methodologies (such as cohort and comparative studies) using DSM-III system criteria convincingly pointed out to the existence of impairment of multiple domains of ADHD patient's life 3,4 . The assessment of quality of life (QoL) indicators is frequently suggested as necessary to a better understanding of ADHD-associated impairment since the correlation between number of symptoms and the impact degree is uncertain ${ }^{5,6}$. Quality-of-life indices have been used in medical practice not only to estimate the impact of different diseases on functioning and well-being but also to compare outcomes between different treatment modalities. Although no single definition of quality of life is universally accepted, most experts agree that the scope of its concept should be centered on the individual's subjective perception of the quality of his or her own life, a consensus based on findings of sociological studies demonstrating that objective conditions of life (education, income etc.) might be only marginally related to the subjective experience of quality of life $\mathrm{f}^{7,8}$.

The Adult ADHD Quality of Life Questionnaire (AAQoL) 9 is a specially designed questionnaire to evaluate the impact of ADHD on patients' QoL. Its structure was developed based on systematization of a data set of symptoms and disease impact collected with their own patients, with specialists in ADHD and in specific literature. This data allowed a conceptual model of the impact of adult ADHD on subject's quality of life. In the validation study the analysis of psychometric properties of the original scale has revealed a global internal consistency of 0.93 and from 0.75 to 0.93 for each of four proposed subscales ${ }^{9}$. The purpose of this study was to investigate its reliability and construct validity in a sample of adult ADHD patients in Brazil. 


\section{Sample and methods}

This study was approved by IPUB - UFRJ Ethics Committee. Seventy-six (76) men and women of 18 to 60 years of age were enrolled. All study subjects signed an informed consent form. Three groups of this study is consisted of: a) ADHD subjects (ADHD Group); b) subjects with ADHD symptoms, but with insufficient symptoms for diagnosis (Subsyndromic Group), and c) normal controls matched for age, sex and education (Control Group). The exclusion criteria for this study were: a) presence of a non-stabilized clinical disease; b) presence of a clinical disease that would potentially compromise daily life activities (lung diseases, heart diseases, joint disease, chronic pain syndromes etc.); c) presence of current major depressive episode (at the time of study enrollment); d) presence of suicidal ideation, and e) presence of current abuse or dependence of alcohol or psychoactive substances.

The first phase is consisted of a validation study of the instrument, involving a two-hypothesis testing. In the first one, an inverse correlation between AAQoL scores and the number of ADHD symptoms has been assumed, i.e., the greater the number of symptoms, the worse the QoL indexes. For testing this hypothesis, two distinct analyses were used: a) a comparison of all three groups to verify if ADHD subjects would have lower QoL than subjects with subsyndromic clinical picture; the latter would have lower QoL in comparison to controls and b) a within-group comparison to verify if patients with a more severe picture of ADHD (i.e., with greater number of symptoms) would have lower quality of life compared to those with the same diagnosis, despite portraying lower symptomatic severity. The second hypothesis supposed that QoL would be lower in the presence of comorbidities. Additionally, they further tried to investigate the existence of a correlation between AAQoL scores and SF-36 scores, a non-disease specific QoL instrument which was selected because it was used in the validation study of the original AAQoL scale.

The second phase comprised a reliability study, involving assessment of internal consistency of items and stability of scale over time. Internal consistency of the instrument was assessed by Cronbach's alpha and Spearman's correlation coefficient. The assessment of scale temporal stability used a test-retest methodology ${ }^{10}$ with a 15 day interval, during which neither a significant change in patient's general behavior is expected nor the remembrance of a previously administered questionnaire and the given answers.

All patients were enrolled consecutively and voluntarily in Attention Deficit Study Group (GEDA) of UFRJ Institute of Psychiatry. For ADHD diagnosis, according to DSM-IV criteria, Module K-SADS-PL Diagnostic Interview (adapted version 6.0) was used and, for psychiatric comorbidities diagnosis, MINI Plus ${ }^{11}$ was used. For ADHD severity analysis, ASRS - Adult ADHD Self-Report Scale, which was previously validated into Portuguese by our group ${ }^{12}$, was used.

Only ADHD subjects having six or more current and past symptoms of at least one symptomatic dimension were included in ADHD Group. Although this criterion may be considered very restrictive and may reduce the number of ADHD diagnosis, several studies investigating drug treatment of adults with ADHD have used this same symptom severity criterion ${ }^{13}$. This criterion was selected due to the fact that it allows the selection of a sample of ADHD patients with lower risk of false-positive diagnoses.

Subjects with symptomatic persistence, i.e., those reporting at least six past symptoms of inattention and/or hyperactivity, but having only four or five current symptoms, were included in Subsyndromic Group. Subjects with four or five past symptoms of at least one of symptomatic dimensions (inattention and hyperactivity-impulsivity) reporting four or more current symptoms were also included in this group. Of note, past symptoms were considered positive if they began before twelve years of age rather than seven years of age as proposed by DSM-IV, according to a widely accepted review of some authors ${ }^{14}$ due to the low empiric validity of age limit established by DSM ${ }^{15}$.

Subjects having less than four current symptoms in both modules, regardless of the number of past symptoms, comprised the Control Group. This criterion for current symptoms has been chosen considering that subjects with three symptoms in at least one symptomatic dimension - despite having symptoms since childhood - did not have comorbidity profile and functional impairment similar to ADHD patients group with DSM-IV diagnosis ${ }^{16}$. Similar results were obtained by Kooij et al. (2005) ${ }^{17}$, who have demonstrated that adults with four or more symptoms had greater functional impairment than those with three or less symptoms. Subjects reporting less than four past symptoms in both modules, with less than six current symptoms, were also considered controls, as the presence of current symptoms without past symptoms in a significant number may suggest an etiology other than ADHD.

A significance level of 5\% was adopted in all statistic tests applied. Chi-square test and analysis of variance were used to compare groups for demographic variables and Shapiro-Wilk test was used to verify data normal distribution, prior to every analysis. The correlation of ASRS and SF-36 scales scores with AAQoL scale scores was assessed by Pearson correlation coefficient (r). Spearman correlation coefficient (rs) was used to assess correlation between scores of $\mathrm{K}$ SADS-PL questionnaire and scores of the AAQoL scale. Differences between groups for mean AAQoL scale scores were compared by Bonferroni multiple comparison tests. Student's t-test was used to compare subgroups of ADHD patients with and without the presence of comorbidities for mean AAQoL scale scores. Internal consistency of AAQoL subscales scores and total score was assessed by Cronbach's alpha and correlations between subscales assessed by Pearson correlation coefficient. Stability over time was assessed by matched t-test comparing score results in both applications and by ICC (intra-class correlation coefficient).

\section{Results}

The sample is consisted of $29 \mathrm{ADHD}$ patients, 18 subjects with ADHD symptoms that do not met full criteria for the diagnosis (subsyndromic form) and 29 control subjects without ADHD. No statistically significant difference was found across groups for demographic variables $(p>0.05)$. Both ADHD and subsyndromic group had one or more comorbid psychiatric diagnoses. Table 1 shows descriptive analyses of each group.

ADHD severity was measured by the score obtained by selfcompleted ASRS scale, computing scores referring to the sum of scores of 9 items of inattention and also referring to the sum of 9 items of hyperactivity/impulsivity, in addition to total score (the sum of 18 items of the scale). In a comparison between ADHD and Control Groups, statistically significant differences were found between groups for total score $(\mathrm{p}<0.001)$ and Inattention and Hyperactivity scores $(\mathrm{p}<0.001$ for both), with averages in Control Group found to be lower than in ADHD Group. In a comparison between ADHD and Subsyndromic Groups for mean scores in ASRS scale, statistically significant differences were found across groups for total score $(\mathrm{p}=0.003)$ and also for Inattention and Hyperactivity scores ( $\mathrm{p}=0.028$ and $\mathrm{p}=0.012$, respectively), with averages in Subsyndromic Group found to be lower than in ADHD Group. In a comparison between Subsyndromic and Control Groups for mean scores in ASRS scale, statistically significant differences were found across groups for total score $(\mathrm{p}<0.001)$ and Inattention and Hyperactivity scores ( $<<0.001$ and $p=0.001$, respectively), with averages in Control Group found to be lower than in ADHD Group.

Scores in four different AAQoL subscales were evaluated in all 3 groups, categorized according to K-SADS PL clinical interview, as shown in table 2.

Correlations between ASRS scores (ADHD severity) and four AAQoL subscales are shown in table 3.

Scores correlation obtained with SF-36 and AAQoL scales, are shown in table 4, taking into consideration groups categorized according to a clinical interview using K-SADS PL.

In table 5 , correlation results between presence of psychiatric comorbidities, as assessed by interview with MINI Plus, and AAQoL indicators of QoL are shown. Comorbidities profile basically consisted of anxiety and mood disorders, and, for the latter, past events.

Internal consistency of the scale was assessed in all three study groups, as shown in table 6; stability analysis is shown in table 7. 
Table 1. Demographics by study group

\begin{tabular}{|c|c|c|c|c|}
\hline \multirow[b]{2}{*}{ Demographics } & \multicolumn{3}{|c|}{ Group } & \multirow[b]{2}{*}{ Comparison } \\
\hline & $\begin{array}{c}\text { ADHD } \\
(n=29)\end{array}$ & $\begin{array}{c}\text { SUB } \\
(n=18)\end{array}$ & $\begin{array}{l}\text { Control } \\
(\mathrm{n}=29)\end{array}$ & \\
\hline \multicolumn{5}{|l|}{ Age (years) } \\
\hline Mean (sd) & $33.2(9.7)$ & 33.1 (11.3) & $30.2(8.7)$ & $p=0.449$ \\
\hline \multicolumn{5}{|l|}{ Gender } \\
\hline Female & $17(58.6 \%)$ & $8(44.4 \%)$ & $17(58.6 \%)$ & \multirow[t]{2}{*}{$p=0.572$} \\
\hline Male & $12(41.4 \%)$ & $10(55.6 \%)$ & $12(41.4 \%)$ & \\
\hline \multicolumn{5}{|l|}{ Race } \\
\hline African-American & $23(79.3 \%)$ & $13(72.2 \%)$ & $25(86.2 \%)$ & \multirow[t]{3}{*}{$p=0.683$} \\
\hline Other: Latino & $3(10.3 \%)$ & $1(5.6 \%)$ & $1(3.4 \%)$ & \\
\hline Other: Mixed & $0(0.0 \%)$ & $0(0.0 \%)$ & $1(3.4 \%)$ & \\
\hline Did not state & $2(6.9 \%)$ & $3(16.7 \%)$ & $2(6.9 \%)$ & \\
\hline African-American & $1(3.4 \%)$ & $1(5.6 \%)$ & $0(0.0 \%)$ & \\
\hline \multicolumn{5}{|l|}{ Comorbidities } \\
\hline None & $12(41.4 \%)$ & $9(50.0 \%)$ & $17(58.6 \%)$ & \\
\hline More than one & $17(58.6 \%)$ & $9(50.0 \%)$ & $12(41.4 \%)$ & \\
\hline
\end{tabular}

SUB: subsyndromic.

Table 2. Ratings of the AAQoL scale, by study group

\begin{tabular}{l|c|c|c|c|c}
\hline \multirow{2}{*}{ Grupos } & \multicolumn{4}{c}{ AAQoL Scale } \\
\cline { 2 - 6 } & Total & Productivity & Psychological health & Life perspectives & Relationship \\
\hline ADHD $(n=29)$ & $36.8(13.2)$ & $29.1(15.5)$ & $34.2(18.6)$ & $49.7(16.5)$ & $39.5(16.8)$ \\
\hline SUB $(n=18)$ & $49.0(16.8)$ & $43.3(25.0)$ & $53.0(19.4)$ & $53.7(16.5)$ & $50.3(17.9)$ \\
\hline Control $(n=29)$ & $62.1(16.8)$ & $62.5(20.3)$ & $59.9(20.3)$ & $64.2(19.6)$ & $61.0(19.6)$ \\
\hline Total sample $(n=76)$ & $49.4(18.9)$ & $45.2(24.5)$ & $48.5(22.4)$ & $56.2(18.7)$ & $50.3(20.3)$ \\
\hline ANOVA - Bonferroni (p) & & & & & 0.008 \\
\hline ADHD x CONT & $<0.001$ & $<0.001$ & $<0.001$ & 0.000 & $<0.001$ \\
\hline ADHD x SUB & 0.033 & 0.059 & 0.006 & 0.154 \\
\hline SUB x CONT & 0.019 & 0.006 & 0.720 & 0.158 & 0.156 \\
\hline
\end{tabular}

SUB: subsyndromic; CONT: control.

Table 3. Correlation between ASRS scores and $A A O D L$ scale ratings

\begin{tabular}{l|c|c|c|c}
\hline \multirow{2}{*}{ Escala AA0LL } & \multicolumn{4}{c}{ Total ASRS - Groups } \\
\cline { 2 - 5 } & $\begin{array}{c}\text { Total sample } \\
(\mathrm{n}=76)\end{array}$ & $\begin{array}{c}\text { ADHD group } \\
(\mathrm{n}=29)\end{array}$ & $\begin{array}{c}\text { SUB group } \\
(\mathrm{n}=18)\end{array}$ & $\begin{array}{c}\text { Control group } \\
(\mathrm{n}=29)\end{array}$ \\
\hline Productivity & $r=-0.81^{*}$ & $r=-0.13$ & $r=-0.80^{*}$ & $r=-0.83^{*}$ \\
\hline Psychological health & $r=-0.59^{*}$ & $r=0.13$ & $r=-0.38$ & $r=-0.64^{*}$ \\
\hline Life perspectives & $r=-0.42^{*}$ & $r=0.24$ & $r=-0.28$ & $r=-0.45^{*}$ \\
\hline Relationship & $r=-0.62^{*}$ & $r=0.19$ & $r=-0.83^{*}$ & $r=-0.56^{*}$ \\
\hline Total & $r=-0.76^{*}$ & $r=0.10$ & $r=-0.76^{*}$ & $r=-0.78^{*}$ \\
\hline
\end{tabular}

${ }^{*}-p<0,05 ;$ SUB: subsyndromic. 
Table 4. Correlation between SF-36 Scale domain scores and ratings of the AAOOL scale

\begin{tabular}{|c|c|c|c|c|c|}
\hline \multirow{2}{*}{ SF-36 Scale - Domains } & \multicolumn{5}{|c|}{ AAOoL Scale } \\
\hline & Total & Productivity & Psychological health & Life perspectives & Relationship \\
\hline \multicolumn{6}{|l|}{ Total sample $(n=76)$} \\
\hline Functional ability & $r=0.40^{*}$ & $r=0.30^{*}$ & $r=0.47^{*}$ & $r=0.33^{*}$ & $r=0.31^{*}$ \\
\hline Physical role & $r=0.48$ & $r=0.50^{*}$ & $r=0.44^{*}$ & $r=0.21$ & $r=0.41^{*}$ \\
\hline Pain & $r=0.37^{*}$ & $r=0.34^{*}$ & $r=0.42^{*}$ & $r=0.17$ & $r=0.34^{*}$ \\
\hline Overall health status & $r=0.52^{*}$ & $r=0.43^{*}$ & $r=0.53^{*}$ & $r=0.45^{*}$ & $r=0.39^{*}$ \\
\hline Vitality & $r=0.58^{*}$ & $r=0.44^{*}$ & $r=0.71^{*}$ & $r=0.49^{*}$ & $r=0.38^{*}$ \\
\hline Social role & $r=0.62^{*}$ & $r=0.38^{*}$ & $r=0.69 *$ & $r=0.64^{*}$ & $r=0.58^{*}$ \\
\hline Emotional role & $r=0.48^{*}$ & $r=0.35^{*}$ & $r=0.48^{*}$ & $r=0.46^{*}$ & $r=0.41^{*}$ \\
\hline Mental health & $r=0.67^{*}$ & $r=0.45^{*}$ & $r=0.81^{*}$ & $r=0.64^{*}$ & $r=0.55^{*}$ \\
\hline \multicolumn{6}{|l|}{ ADHD Group ( $n=29$ ) } \\
\hline Functional ability & $r=0.34$ & $r=0.14$ & $r=0.42^{*}$ & $r=0.26$ & $r=0.30$ \\
\hline Physical role & $r=0.27$ & $r=0.33$ & $r=0.10$ & $r=0.03$ & $r=0.38^{*}$ \\
\hline Pain & $r=0.13$ & $r=0.07$ & $r=0.20$ & $r=0.04$ & $r=0.21$ \\
\hline Overall health status & $r=0.28$ & $r=0.09$ & $r=0.42^{*}$ & $r=0.25$ & $r=0.21$ \\
\hline Vitality & $r=0.55^{*}$ & $r=0.31$ & $r=0.61^{*}$ & $r=0.55^{*}$ & $r=0.30$ \\
\hline Social role & $r=0.62^{*}$ & $r=0.28$ & $r=0.70^{*}$ & $r=0.61^{*}$ & $r=0.49^{*}$ \\
\hline Emotional role & $r=0.56^{*}$ & $r=0.39^{*}$ & $r=0.47^{*}$ & $r=0.54^{*}$ & $r=0.41^{*}$ \\
\hline Mental health & $r=0.75^{*}$ & $r=0.44^{*}$ & $r=0.89^{*}$ & $r=0.69^{*}$ & $r=0.43^{*}$ \\
\hline \multicolumn{6}{|l|}{ SUB Group $(n=18)$} \\
\hline Functional ability & $r=0.22$ & $r=0.18$ & $r=0.32$ & $r=0.18$ & $r=-0.02$ \\
\hline Physical role & $r=0.53^{*}$ & $r=0.40$ & $r=0.76^{*}$ & $r=0.16$ & $r=0.44$ \\
\hline Pain & $r=0.49^{*}$ & $r=0.41$ & $r=0.52^{*}$ & $r=0.19$ & $r=0.45$ \\
\hline Overall health status & $r=0.46$ & $=0.35$ & $r=0.29$ & $r=0.57^{*}$ & $r=0.32$ \\
\hline Vitality & $r=0.46$ & $r=0.43$ & $r=0.62^{*}$ & $r=0.17$ & $r=0.16$ \\
\hline Social role & $r=0.53^{*}$ & $r=0.34$ & $r=0.63^{*}$ & $r=0.47^{*}$ & $r=0.45$ \\
\hline Emotional role & $r=0.58^{*}$ & $r=0.40$ & $r=0.63^{*}$ & $r=0.40$ & $r=0-.58^{*}$ \\
\hline Mental health & $r=0.60^{*}$ & $r=0.45$ & $r=0.70^{*}$ & $r=0.35$ & $r=0.52^{*}$ \\
\hline \multicolumn{6}{|l|}{ Control group $(n=29)$} \\
\hline Functional ability & $r=0.58^{*}$ & $r=0.49^{*}$ & $r=0.59 *$ & $r=0.43^{*}$ & $r=0.45^{*}$ \\
\hline Physical role & $r=0.59^{*}$ & $r=0.69^{*}$ & $r=0.55^{*}$ & $r=0.27$ & $r=0.29$ \\
\hline Pain & $r=0.42^{*}$ & $r=0.39 *$ & $r=0.46^{*}$ & $r=0.24$ & $r=0.28$ \\
\hline Overall health status & $r=0.55^{*}$ & $r=0.48^{*}$ & $r=0.55^{*}$ & $r=0.44^{*}$ & $r=0.32$ \\
\hline Vitality & $r=0.71^{*}$ & $r=0.52^{*}$ & $r=0.83^{*}$ & $r=0.61^{*}$ & $r=0.45^{*}$ \\
\hline Social role & $r=0.73^{*}$ & $r=0.42^{*}$ & $r=0.72^{*}$ & $r=0.76^{*}$ & $r=0.72^{*}$ \\
\hline Emotional role & $r=0.44^{*}$ & $r=0.30$ & $r=0.43^{*}$ & $r=0.45^{*}$ & $r=0.31$ \\
\hline Mental health & $r=0.58^{*}$ & $r=0.22$ & $r=0.73^{*}$ & $r=0.69^{*}$ & $r=0.51^{*}$ \\
\hline
\end{tabular}

${ }^{*}-p<0,05$; SUB: subsyndromic.

Table 5. Ratings of the AAOLL scale by comorbidity presence

\begin{tabular}{l|c|c|c|c|c}
\hline \multirow{2}{*}{ ADHD Group } & \multicolumn{4}{c}{ AA0oL Scale } & Relationship \\
\cline { 2 - 6 } & Total & Productivity & Psychological health & Life perspectives & $49.2(14.7)$ \\
\hline Without comorbidities $(\mathrm{n}=12)$ & $45.6(11.5)$ & $35.8(19.7)$ & $44.8(16.0)$ & $59.1(12.8)$ & $32.6(14.9)$ \\
\hline With comorbidities $(\mathrm{n}=17)$ & $30.7(10.8)$ & $24.3(9.8)$ & $26.7(16.9)$ & $43.1(15.8)$ & 0.007 \\
\hline Student's t-test & 0.001 & 0.083 & 0.007 & 0.006 \\
\hline
\end{tabular}

Table 6. Internal consistency of the AAOoL scale

\begin{tabular}{l|c|c|c|c}
\hline \multirow{2}{*}{ AA0oL Scale } & \multicolumn{4}{c}{ Cronbach's $\alpha$} \\
\cline { 2 - 5 } & Total sample $(\mathrm{n}=76)$ & ADHD Group $(\mathrm{n}=29)$ & SUB Group $(\mathrm{n}=18)$ & Control Group $(\mathrm{n}=29)$ \\
\hline Produtividade & 0.92 & 0.77 & 0.94 & 0.88 \\
\hline Saúde psicológica & 0.84 & 0.74 & 0.81 & 0.84 \\
\hline Perspectivas de vida & 0.84 & 0.74 & 0.77 & 0.89 \\
\hline Relacionamentos & 0.73 & 0.56 & 0.66 & 0.76 \\
\hline Total & 0.85 & 0.62 & 0.88 & 0.81 \\
\hline
\end{tabular}


Table 7. Comparison between both applications of the AAOoL scale

\begin{tabular}{|c|c|c|c|c|}
\hline \multirow{2}{*}{ AA0oL Scale } & \multicolumn{2}{|c|}{ Scores - mean (sd) } & \multirow{2}{*}{ t-test } & \multirow{2}{*}{ ICC } \\
\hline & 1st application & $2^{\text {nd }}$ application & & \\
\hline \multicolumn{5}{|l|}{ Total sample $(n=57)$} \\
\hline Total & $46.4(17.7)$ & $47.5(18.3)$ & 0.373 & 0.89 \\
\hline Productivity & $41.1(22.7)$ & $42.3(23.7)$ & 0.428 & 0.90 \\
\hline Psychological health & $46.0(21.7)$ & $47.4(21.1)$ & 0.409 & 0.81 \\
\hline Life perspectives & $54.2(17.0)$ & $53.5(17.2)$ & 0.641 & 0.78 \\
\hline Relationship & $48.0(20.4)$ & $50.5(19.1)$ & 0.181 & 0.74 \\
\hline \multicolumn{5}{|l|}{ ADHD Group ( $n=18$ ) } \\
\hline Total & $34.6(12.1)$ & $35.9(14.1)$ & 0.591 & 0.69 \\
\hline Productivity & $26.4(13.2)$ & $28.8(15.9)$ & 0.454 & 0.53 \\
\hline Psychological health & $31.9(17.8)$ & $33.7(19.1)$ & 0.562 & 0.72 \\
\hline Life perspectives & $49.2(17.0)$ & 46.1 (18.3) & 0.168 & 0.83 \\
\hline Relationship & $36.2(17.6)$ & $40.0(16.1)$ & 0.273 & 0.58 \\
\hline \multicolumn{5}{|l|}{ SUB Group $(n=17)$} \\
\hline Total & $49.0(16.8)$ & $49.7(17.4)$ & 0.690 & 0.91 \\
\hline Productivity & $43.3(25.0)$ & $42.8(25.4)$ & 0.782 & 0.96 \\
\hline Psychological health & $53.0(19.4)$ & $53.5(18.5)$ & 0.884 & 0.77 \\
\hline Life perspectives & $53.7(16.5)$ & $55.3(14.7)$ & 0.637 & 0.61 \\
\hline Relationship & $50.3(17.9)$ & $52.8(17.7)$ & 0.471 & 0.68 \\
\hline \multicolumn{5}{|l|}{ Control Group ( $n=18$ ) } \\
\hline Total & $57.6(16.4)$ & $58.7(16.3)$ & 0.563 & 0.89 \\
\hline Productivity & $56.2(18.7)$ & $57.4(21.1)$ & 0.510 & 0.92 \\
\hline Psychological health & $55.3(20.4)$ & $57.4(17.8)$ & 0.514 & 0.76 \\
\hline Life perspectives & 60.4 (16.3) & $60.2(15.6)$ & 0.936 & 0.81 \\
\hline Relationship & $59.4(19.2)$ & $60.5(18.3)$ & 0.722 & 0.77 \\
\hline
\end{tabular}

ICC: intra-class correlation coefficient; SUB: subsyndromic.

\section{Discussion}

The analysis of construct validity of the Portuguese version of AAQoL scale was based on the presupposition that higher scores in this scale (i.e., better indexes of QoL) should be associated to lower numbers of ADHD symptoms. This inverse relationship should be observed not only in the group of patients with full diagnosis of the disorder (the more severe disorder symptoms, the worse quality of life) but also in subsyndromic cases (the latter, with lower symptom severity and, therefore, with better quality of life). Therefore, it would be important that restrictive criteria would be used to delineate more precisely each group; the use of more restrictive criteria using DSM-IV system (the need of a full diagnosis in childhood) and the use of a semi-structured interview intended to meet this need. In a recent study ${ }^{18}$ which proposes a distinct scale of QoL for adults with ADHD (ADHD Impact Module for Adults - AIM-A), employing a methodology similar to that used in validation study of the original AAQoL, as for a number of other studies in literature, enrolled patients were assessed without using a semi-structured interview both for ADHD diagnosis and comorbidities.

Classification according to ASRS score severity in mild (0-18), moderate (19-20), and severe (21 or more), as used in the original paper of $\operatorname{Brod}^{9}$, was not applicable to this study, since, in ADHD group, 29 patients $(100 \%)$ had scores that would categorize them as "severe ADHD"; then, an analysis of symptoms severity in the total sample and in all 3 groups was performed. In total sample, statistically significant negative correlations between total score of ASRS scale and AAQoL subscales scores were found, indicating that the higher the ASRS score, the lower AAQoL subscales score. Correlation of -0.76 between total scores of ASRS and AAQoL scales was statistically significant. This finding is supported by epidemiological studies showing that the number of ADHD symptoms is associated to worst indicators of psychosocial functioning ${ }^{3}$. In the Control Group, statistically significant negative correlations were found between ASRS total score and AAQoL subscales score, indicating again that the higher the ASRS score, the lower AAQoL subscales score. Correlation of -0.78 between total scores of ASRS and AAQoL scales was also statistically significant. In ADHD and Subsyndromic Groups, correlations were non-significant or significant only for some subscales and not for others. These results seem to indicate that although there is a correlation between ADHD symptomatology severity and QoL indexes, comparison between diagnostic categories - i.e., ADHD and Subsyndromic - did not reveal to be significant, possibly due to the limited sample size of each one.

In a comparison between ADHD and Control groups for mean scores in the AAQoL scale, statistically significant differences in total score and scores of all subscales point out to a significant discriminatory effect between both groups for quality of life. In a comparison between ADHD and Subsyndromic groups, statistically significant differences occurred only in total score and in Psychological Health subscale score; in Productivity subscale, the difference was marginally significant. In a comparison between Subsyndromic and Control groups, statistically significant differences were found in total score and Productivity subscale score, but not in the remaining. These results suggest a strong correlation between construct measured by AAQoL and ADHD diagnosis, although comparison between group with formal diagnosis (ADHD) and subsyndromic form group and between the latter with control group provided less significant results as a whole. It must be noted, however, that a higher number of correlations augment the chances of a significant correlation by chance.

In an inter-group comparison between patients from ADHD Group with and without comorbidities, statistically significant differences were found in total score and scores of Psychological Health, Life Outlook, and Relationships subscales, with averages in the Group without Comorbidities being always higher than those in the Group with Comorbidities. Only in Productivity subscale, a 
difference between group averages was non-significant. The findings revealing that the presence of comorbidity was associated with worse QoL in accordance to our previous hypothesis.

In a comparison with other instrument of quality of life assessment, SF-36, which is still widely used in our field, statistically significant positive correlations between total score of the AAQoL scale and scores of scale SF-36 domains ( $\mathrm{p}<0.01$ for all domains), ranging between $r=0.37$ for Pain and $r=0.67$ for Mental Health in total sample, were found. In Productivity, Psychological Health, and Relationships subscales of the AAQoL scale, correlations were all significant.

The internal consistency of the scale was a highly significant (0.85) for AAQoL total score, ranging from 0.73 to 0.92 for different subscales, in the total sample. Similar results were seen in ADHD, Subsyndromic and Control Groups, with Productivity subscale being the one with higher coefficient in all three groups.

The comparison between two administrations of AAQoL, at a 15-day interval, revealed that there were no statistically significant differences in AAQoL total score and also in AAQoL subscales in the total sample, ADHD group and subjects with subsyndromic form, as well as in controls, indicating stability over time.

\section{Conclusion}

The Portuguese version of AAQoL has revealed to have excellent construct validity in assessment of different quality of life indicators in ADHD patients (Productivity, Psychological Health, Life Outlook, and Relationships). This scale has shown a high correlation to another widely used instrument (SF-36), good stability over time and excellent internal consistency of items included.

\section{Sponsorship}

This study was sponsored by Janssen-Cilag Brasil

\section{Potential conflicts of interest}

Paulo Mattos is a member of the advisory committee and speaker for Janssen-Cilag and Novartis laboratories. Daniel Segenreich is a speaker for Janssen-Cilag and Novartis.

\section{References}

1. Barkley R, Smallish M, Fletcher K. The persistence of attention-deficit/ hyperactivity disorder into young adulthood as a function of reporting source and definition of disorder. J Abnorm Psychol. 2002;111(2):279-89.

2. Biederman J, Mick E, Faraone SV. Age-dependent decline of symptoms of attention deficit hyperactivity disorder: impact of remission definition and symptom type. Am J Psychiatry. 2000;157(5):816-8.
3. Pastura G, Mattos P, Pruffer A. Desempenho escolar e transtorno do déficit de atenção. Rev Psiq Clín. 2005;32(6):324-9.

4. Kessler RC, Adler LA, Barkley R, Biederman J, Conners CK, Faraone SV, et al. Patterns and predictors of attention-deficit/hyperactivity disorder persistence into adulthood: results from the national comorbidity survey replication. Biol Psychiatry. 2005;1,57(11):1442-51.

5. Barkley RA, Cunningham CE, Gordon M, Faraone SV, Lewandowski L, Murphy KR. ADHD symptoms vs. impairment: revisited. ADHD Report. 2006;14(2):1-9.

6. Gathje RA, Lewandowski L, Gordon M. The Role of Impairment in the Diagnosis of ADHD. J Attend Disord. 2008;11(5):529-37.

7. Larson R. Thirty years of research on the subjective well-being of older Americans. J Gerontol. 1978;33:109-25.

8. Gill TM, Feinstein AR. A critical appraisal of the quality of quality-of-life measurements. JAMA. 1994;272:619-26.

9. Brod M, Johnston J, Able S, Swindle R. Validation of the adult attentiondeficit/hyperactivity disorder quality-of-life scale (AAQoL): a diseasespecific quality-of-life measure. Qual Life Res. 2006;15:117-29.

10. Bland JM, Altman DG. Statistical methods for assessing agreement between two methods of clinical measurement. Lancet. 1986;1(8476):307-10.

11. Sheehan DV, Lecrubier Y, Sheehan KH, Amorim P, Janavs J, Weiller E, et al. The Mini-International Neuropsychiatric Interview (M.I.N.I.): the development and validation of a structured diagnostic psychiatric interview for DSM-IV and ICD-10. J Clin Psychiatry. 1998;59(Suppl 20):22-3.

12. Mattos P, Segenreich D, Saboya S, Louzã M, Dias G, Romano M. Adaptação transcultural para o português da escala Adult Self-Report Scale para avaliação do transtorno de déficit de atenção/hiperatividade (TDAH) em adultos Rev Psiq Clín. 2006;33(4):188-94.

13. Spencer T, Biederman J, Wilens T, Doyle R, Surman C, Prince J, et al. A large, double-blind, randomized clinical trial of methylphenidate in the treatment of adults with attention deficit/hyperactivity disorder. Biol Psychiatry. 2005;57(5):456-63.

14. Barkley RA, Biederman J. Toward a broader definition of the age-of-onset criterion for attention deficit hyperactivity disorder. J Am Acad Child Adolesc Psych. 1997;36:1204-10.

15. Rohde LA, Biederman J, Zimmermann H, Schmitz M, Martins S, Tramontina S. Exploring ADHD age of-onset criterion in Brazilian adolescents. Eur Child Adolesc Psychiatry. 2000;9(3):212-8.

16. Faraone SV, Biederman J, Spencer T, Mick E, Murray K, Petty C, et al. Diagnosing adult attention deficit hyperactivity disorder: are late onset and subthreshold diagnoses valid? Am J Psychiatry. 2006;163:1720-9.

17. Kooij JJS, Buitellaar JK, Van den OORD EJ, Furer JW, Rijnders CA, Hodiamont PPG. Internal and external validity of attention-deficit hyperactivity disorder in a population-based sample of adults. Psychol Med. 2005:35:817-27.

18. Landgraf JM. Monitoring quality of life in adults with ADHD: reliability and validity of a new measure. J Attend Disord. 2007;11(3):351-62. 